\title{
Angiolymphoid hyperplasia with eosinophilia involving the lacrimal gland: case report
}

\author{
H T COOK' AND N D STAFFORD
}

From the Departments of 'Histopathology, and 'Otolarygology, St Mary's Hospital, London

SUMMARY A case is described of a 25-year-old male who developed angiolymphoid hyperplasia with eosinophilia involving the tissue over the left parotid gland and subsequently involving the right lacrimal gland with proptosis. Treatment was by excision.

Angiolymphoid hyperplasia with eosinophilia (ALHE) is an uncommon lesion which presents as one or more nodules involving the dermis or subcutaneous tissues mainly of the head or neck but occasionally at other sites.' It is characterised by lymphoid aggregates with germinal centres, tissue eosinophilia, vascular proliferation with typical plump endothelial cells, and variable fibrosis. In some cases blood eosinophilia is present. We report a case in which the initial presentation was with a swelling over one parotid gland with subsequent involvement of the contralateral lacrimal gland.

\section{Case report}

A 25-year-old male of Asian descent, but resident in the UK since birth, presented with a three-month history of a soft diffuse swelling in the region of the left parotid gland. The swelling was painless, and there were no other abnormalities on clinical examination of the head or neck. A parotid sialogram was normal, and a diagnosis of a lipoma overlying the parotid gland was made. The swelling slowly enlarged over the following 10 months, and therefore a superficial parotidectomy was undertaken. By this time the patient had begun to develop slight swelling in the region of the right lacrimal gland. A differential white blood cell count at this time showed $66 \%$ neutrophils, $23 \%$ lymphocytes, and $11 \%$ eosinophils.

Over the next nine months the swelling above the right eye increased and a marked proptosis developed (Fig. 1). There was no ophthalmoplegia, but the patient experienced considerable discomfort. A CT scan demonstrated the lacrimal gland swelling

Correspondence to Dr H T Cook, Department of Histopathology, St Mary's Hospital, Praed Street, London W2 1NY.

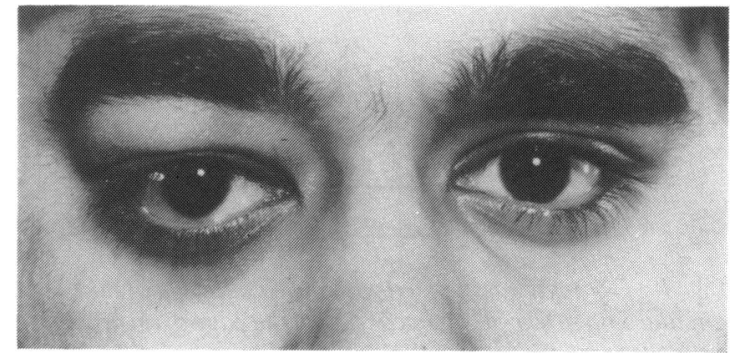

Fig. 1 There is downward displacement of the globe by swelling in the lacrimal region.

and also swelling of the medial, lateral, and inferior rectus muscles of the right orbit (Fig. 2). Excision of the lacrimal gland was carried out. At operation it

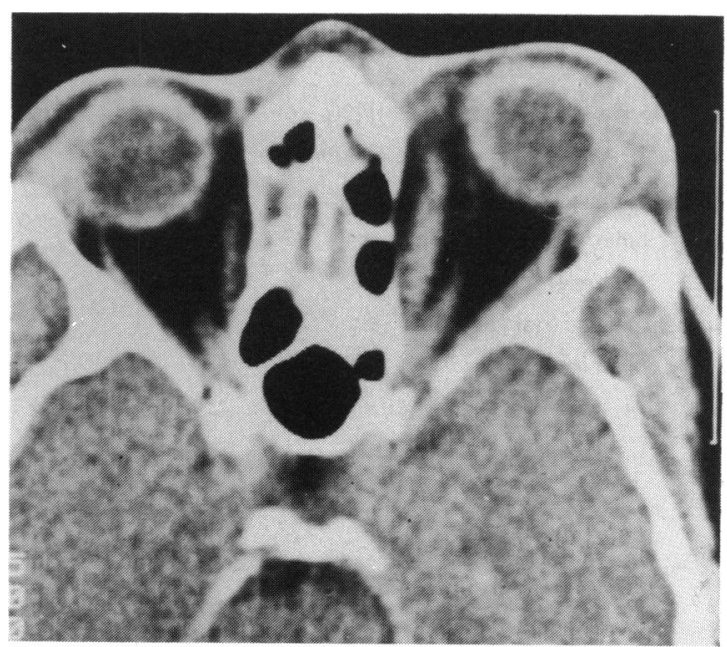

Fig. 2 CT scan demonstrating mild proptosis and a mass above and lateral to the right globe. 


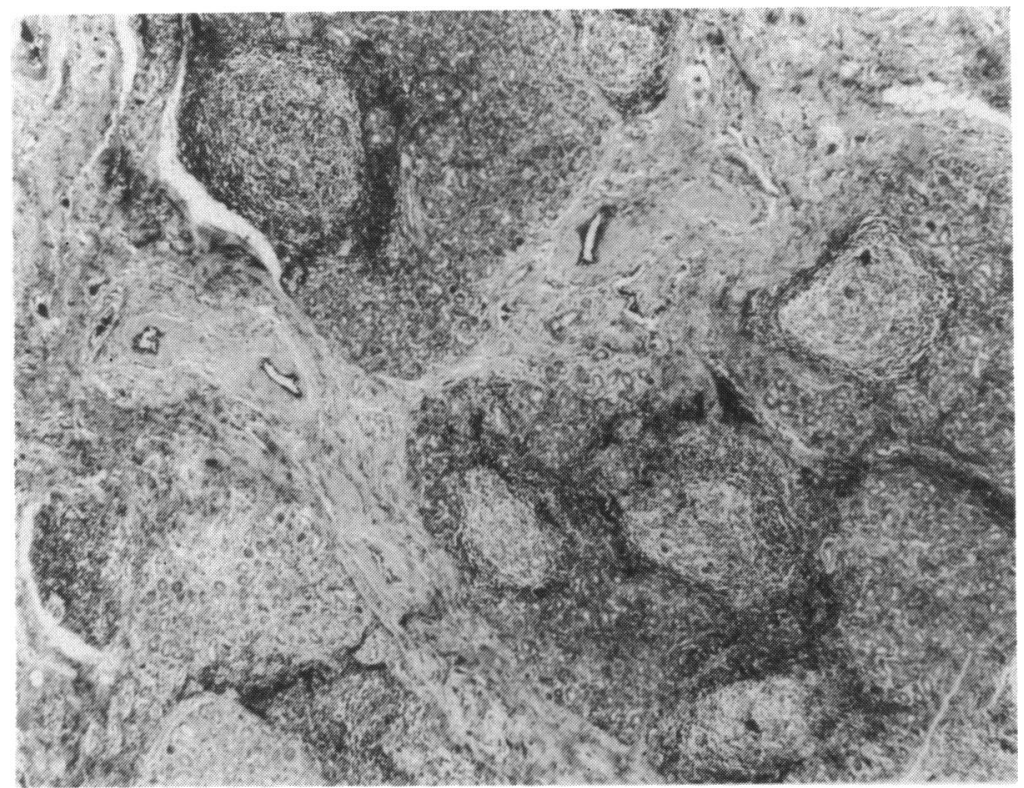

Fig. 3 Photomicrograph of lacrimal gland showing fibrosis and prominent lymphoid follicles with germinal centre formation. Haematoxylin and eosin, $\times 45$.

was found to be infiltrated by a mass arising from its anterior part. Some of the apparently normal gland was left in order to facilitate tear production, and the operation was followed by rapid resolution of the proptosis and associated symptoms.

The patient was last seen 10 months after his second operation and had no evidence of any other swellings, either in the head and neck region or elsewhere over the body.

\section{PATHOLOGY}

The specimen from the parotid region consisted of part of the parotid gland and superficial fibrous tissue measuring $9.0 \times 4 \times 1.5 \mathrm{~cm}$. The lacrimal gland specimen was two pieces of light brown tissue measuring in total $3.0 \times 2.0 \times 0.6 \mathrm{~cm}$. Histologically the two specimens showed similar features which in the parotid specimen were predominantly in the tissue superficial to the parotid gland, while the deeper part of the gland was unaffected. In the second specimen the changes were seen within the lacrimal gland with extension into the surrounding connective tissue. In both specimens there was marked fibrosis and prominent lymphoid follicles, most of which contained germinal centres (Fig. 3). Within the fibrous stroma were many lymphocytes, eosinophils, and mast cells and con-

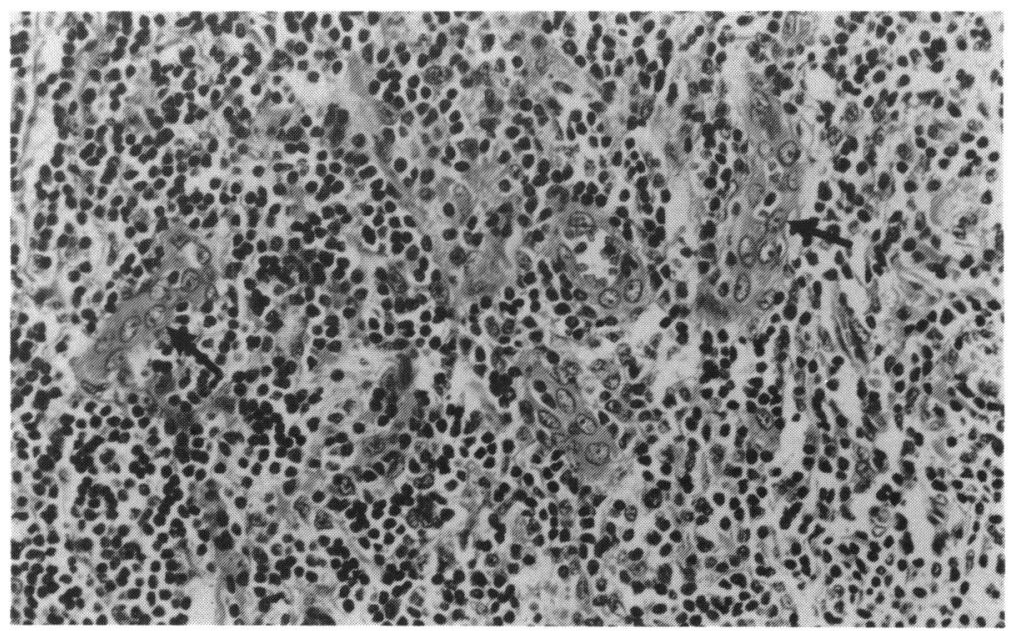

Fig. 4 Photomicrograph of an area of vascular proliferation within the lacrimal gland. Note the vessels lined by plump endothelial cells (arrows) and the lymphocytic infiltration. Haematoxylin and eosin, $\times 190$. 
siderable capillary proliferation. Many of these proliferating vessels were lined by plump endothelial cells with large vesicular nuclei (Fig. 4). In occasional areas cells of this type were forming small aggregates with no apparent lumen. The appearances in both specimens were those of angiolymphoid hyperplasia with eosinophilia.

\section{Discussion}

ALHE was first reported in $1969 .{ }^{2}$ It is closely related to Kimura's disease, ${ }^{3}$ an entity which has been mainly described in China and Japan, and it has been argued that Kimura's disease is part of the spectrum of ALHE. ${ }^{145}$ Others, however, have emphasised the differences, pointing out that Kimura's disease has different clinical and pathological characteristics.' In particular Kimura's disease is said to affect predominantly young males with a high incidence of blood eosinophilia and histologically to show more fibrosis and fewer distinctive endothelial cells. It seems probable that the degree of fibrosis may depend on the duration of the disease before biopsy.

In a report of 116 patients with ALHE submitted to the Armed Forces Institute of Pathology ${ }^{1}$ the anatomical sites of the lesions were face and scalp in 100 , trunk 4 , extremities 12 , and miscellaneous 2 . In only one case was the diagnosis made preoperatively. Hidayat et al. ${ }^{6}$ have reported eight cases of ALHE involving the orbit; in none of these cases was the tumour said to involve the lacrimal gland. Eisenberg and Lowlicht ${ }^{4}$ have reported a case similar to ours in a 34-year-old female who presented with ALHE involving the right cheek and subsequently developed lacrimal gland involvement.

The consensus is that ALHE is a reactive inflammatory process, and the presence of eosinophils and occasional blood eosinophilia has led to speculation that it represents in an infectious or allergic process or a response to parasitic infection. No parasites or micro-organisms have ever been described within the lesions. Fernandez et al. ${ }^{7}$ have demonstrated the presence of renin-containing cells in some cases of ALHE and speculate that it may have an angiogenic role. Staining with a polyclonal antibody to human renin was negative in the present case.

ALHE can be successfully treated by local surgery, ${ }^{6}$ though complete excision may be difficult. ${ }^{8}$ In addition radiation therapy has been effective ${ }^{9}$ and intralesional injections of corticosteroids have been successful in some cases.

Professor E Wilson Jones and Dr R W Cox are thanked for advice on the histology of this case.

\section{References}

1 Olsen TG, Helwig EB. Angiolymphoid hyperplasia with eosinophilia. A clinicopathological study of 116 patients. J Am Acad Dermatol 1985; 12: 781-96.

2 Wells GC, Whimster IW. Subcutaneous angiolymphoid hyperplasia with eosinphilia. Br J Dermatol 1969; 81: 1-15.

3 Kimura T, Yoshimura S, Ishikawa E. On the unusual granulation combined with hyperplastic changes of lymphatic tissue. Trans Soc Pathol Jpn 1948; 37: 179-80.

4 Eisenberg E, Lowlicht R. Angolymphoid hyperplasia with eosinophils: a clinicopathological conference. J Oral Pathol 1985; 14: 216-23.

5 Reed RJ, Terazakis N. Subcutaneous angiolymphoid hyperplasia with eosinophilia (Kimura's disease). Cancer 1972; 29: 489-97.

6 Hidayat AA, Cameron JD, Font RL, Zimmerman LE. Angiolymphoid hyperplasia with eosinophilia (Kimura's disease) of the orbit and ocular adnexa. Am J Ophthalmol 1983; 96: 176-89.

7 Fernandez LA, Olsen TG, Barwick KW, Sanders M, Kaliszewski $\mathrm{C}$, Inagami T. Renin in angiolymphoid hyperplasia with eosinophilia. Arch Pathol Lab Med 1986; 110: 1131-5.

8 Tham K-T, Leung P-C, Saw D, Gwi E. Kimura's disease with salivary gland involvement. Br J Surg 1981; 68: 495-7.

9 Iguchi Y, Inoue T, Shimono M, Yamamura T, Shigematsu T, Takahashi S. Kimura's disease and its relation to angiolymphoid hyperplasia with eosinophilia: report of three cases and review of the literature. J Oral Pathol 1986; 15: 132-7.

Accepted for publication 2 July 1987. 